\title{
Eliciting thematic reanalysis effects: The role of syntax-independent information during parsing
}

\author{
Ina Bornkessel \\ Max-Planck-Institute of Cognitive Neuroscience, Leipzig, \\ Germany \\ Matthias Schlesewsky \\ Junior Research Group Neurolinguistics, University of Marburg, \\ Marburg, Germany \\ Angela D. Friederici \\ Max-Planck-Institute of Cognitive Neuroscience, Leipzig, \\ Germany
}

In this paper, we present experimental evidence for the existence of syntax-independent (viz. thematic) reanalysis effects. In an experiment using event-related brain potentials (ERPs), we manipulated the thematic structure of the verb in transitive, unambiguously case marked German verb-final clauses such that the processing of this verb either confirmed the 'canonical' hierarchical thematic ordering between the sentential arguments (active verbs) or required a reversal of this ordering (object-experiencer verbs). The latter elicited a parietal positivity between 300 and $600 \mathrm{~ms}$ post onset, which, as we argue, must be interpreted as reflecting a thematic reanalysis. The second experimental manipulation, i.e., a variation of word order (SO vs. OS), revealed an early positivity at the position of the second

Requests for reprints should be sent to Ina Bornkessel, Max-Planck-Institute of Cognitive Neuroscience, P.O. Box 5003 55, 04303 Leipzig, Germany. Email: bornke@cns.mpg.de

The research reported here was supported by a grant from the Deutsche Forschungsgemeinschaft (DFG) to M.S. and A.D.F. (FOR 375/1-4). The authors would like to thank Stefan Frisch and Gisbert Fanselow for many helpful discussions on issues related to the research reported here and Cornelia Schmidt for help with the data acquisition. Furthermore, the paper has greatly benefited from the comments of Gerry Altmann and two anonymous reviewers.

(C) 2003 Psychology Press Ltd

http://www.tandf.co.uk/journals/pp/01690965.html

DOI: $10.1080 / 01690960244000018$ 
NP in dative-nominative (OS) structures. Again, we account for this effect in terms of a thematic reanalysis, which becomes necessary when the original interpretation of the initial argument as thematically highest-ranking must be revised. We conclude from our data that case marking languages such as German may employ non-syntactic processing routes to determine the thematic interpretation of a sentence.

Many insights about the nature of human sentence processing have been gained from the examination of misanalyses during parsing ('garden path effects'). Specifically, a great deal of research has focused on determining how parsing decisions are made in ambiguous regions and how recovery from garden paths proceeds. While this line of research has led to numerous studies investigating whether various types of non-syntactic linguistic information (e.g. frequency, plausibility, etc.; see for example MacDonald, Pearlmutter, \& Seidenberg, 1994; Trueswell, Tanenhaus, \& Garnsey, 1994) may influence first-pass parsing decisions and, also, reanalysis processes, it has hitherto not been investigated whether a garden path may itself be non-syntactic in nature. Thus, the term 'reanalysis' is generally understood as referring to operations which somehow affect the syntactic representation of a sentence.

Upon closer consideration, however, the question arises of whether this syntactically based characterization of reanalysis is not too narrow, for all that the term 'reanalysis' essentially captures is the need to perform some sort of a recomputation with regard to the analysis of a linguistic input that has been built up so far. There are, of course, certain prerequisites for such a recomputation to be possible or even necessary. First, there must be an ambiguity at a point at which the parser must make a decision, since otherwise there should be no reason for the parser to pursue a wrong analysis in the first place. Second, this ambiguity must be resolvable by preference mechanisms of some sort, i.e. the domain of information in which the ambiguity arises must be hierarchically ordered. While syntactic structure appears to ideally fulfil these criteria, the rich internal structuring that is characteristic of linguistic information in general leads one to suspect that they should also apply in certain non-syntactic domains of information.

In light of these observations, this paper will examine the hypothesis that syntactically independent reanalysis effects should be experimentally observable. First, we will be concerned with showing that the domain of thematic information fulfils the prerequisites for reanalysis stated above, before presenting an experiment using event-related brain potentials (ERPs) which examines thematic reanalysis effects in German. On the basis of the results of this study, we will argue that the characterisation and study of reanalysis effects should be extended to include those based on non-syntactic information. 


\section{THE STRUCTURE OF THE THEMATIC DOMAIN}

In the following, we will be concerned with conceptually motivating reanalysis in a non-syntactic domain, namely with regard to thematic information (i.e., the information coded by the thematic roles borne by the arguments of a sentence). In this regard we will argue that thematic information is (a) potentially ambiguous, (b) processed incrementally, and (c) hierarchically ordered (and thereby likely to be subject to preference mechanisms). In this way, it will become apparent that thematic information is suitably structured for the elicitation of reanalysis effects.

\section{Ambiguity}

Since a reanalysis involves 'recomputing' an analysis of a linguistic input if this analysis turns out to be untenable, perhaps the most important prerequisite for reanalysis effects to occur is the presence of an ambiguous input, i.e., a choice point at which the parser may make the wrong decision. The possibility of thematic ambiguity is illustrated by the sentences in (1).

(1) a. John broke a vase.

b. John broke a leg.

With regard to their surface structure, (1a) and (1b) are identical. However, in (1a) John is the AGENT of the event described by the predicate (or at least its CAUSE, if he should have knocked over the vase accidentally), while in (1b) John presumably does not actively contribute to the breaking of his leg and must therefore be assigned the thematic role of Patient or Theme. Hence, when John is encountered during the parseprocess, there is no way of knowing which thematic role this constituent should be assigned.

In this way, a further important characteristic of thematic information becomes clear: at least from a parsing perspective, thematic structure is independent of syntactic structure. Thus, there is no syntactic ambiguity involved in (1) and the fact that John is a subject fails to predict the thematic role that this argument must be assigned (in general, a one-to-one mapping of thematic roles to syntactic functions (or particular cases) is not possible; cf. Wunderlich, 1985). It thus appears that thematic ambiguities are indeed independent of syntactic ambiguities.

\section{Incremental Processing}

While we have established that thematic information may be ambiguous, this fact in itself will only contribute to reanalysis effects if the parser must make a choice between the various alternatives arising at an ambiguous point. In the following, we will show that this indeed appears to be the case 
by pursuing two lines of argumentation, the first being conceptual and the second empirical in nature.

First, there is solid empirical evidence suggesting that incrementality is one of the basic properties of the human language processor (beim Graben, Saddy, Schlesewsky, \& Kurths, 2000). This observation is captured, for example, in Crocker's (1994) principle of incremental comprehension (cf. also the left-to-right incremental parsing hypothesis, as formulated by Stabler, 1994), which is given in (2).

(2) Principle of Incremental Comprehension (PIC) The sentence processor operates in such a way as to maximize the interpretation and comprehension of the sentence at each stage of processing (i.e., as each lexical item is encountered). (Crocker, 1994; p. 251)

Since proper sentence comprehension depends on a successful assignment of thematic roles to sentential arguments, the PIC leads to the prediction that the processing of thematic information should take place in an incremental manner, just as the processing of syntactic structure does. This assumption that the parser attempts to maximise thematic interpretation with each incoming input item also follows from proposals of an independent thematic processing module which functions independently of and in parallel to the syntactic module (cf. Rayner, Carlson, \& Frazier, 1983).

A second, empirical, piece of evidence that thematic relations are established incrementally stems from experimental studies on the processing of double case ungrammaticalities in German (Frisch, 2000; Frisch \& Schlesewsky, 2001). This type of ungrammaticality is illustrated in (3), from Frisch \& Schlesewsky (2001).

(3) Hans fragt sich, Hans asks himself

a. *... welcher Dichter der Gärtner besuchte. $\ldots$ which $_{\mathrm{NOM}}$ poet the $\mathrm{NOM}_{\mathrm{NO}}$ gardener visited

b. *... welcher Dichter der Ast streifte. $\ldots$ which $_{\text {NOM }}$ poet the NOM $_{\text {branch brushed }}$

The embedded sentences in (3) are ungrammatical because both sentential arguments bear nominative case, a pattern that is not permissible in German. Frisch \& Schlesewsky (2001) report an ERP study in which sentences such as (3a) elicited a biphasic N400-P600 pattern at the position of the second NP. The authors argue that the N400, i.e., a component typically associated with lexical-semantic manipulations (cf. Kutas \& Federmeier, 2000), observed for these structures reflects the processing difficulties arising when two arguments cannot be hierarchised thematically with respect to one another. This interpretation is supported by the 
finding that sentences such as (3b), in which one of the two nominativemarked arguments is animate and the other is inanimate, elicit a P600 but, crucially, no N400 in comparison with grammatical controls. Thus, the processing conflict that arises when a hierarchical thematic ordering cannot be established between the arguments is alleviated by the presence of a thematically relevant feature that allows for such an ordering. Clearly, the observation that sentences such as (3a) elicit a violation that is thematic in nature even before the verb is encountered is a strong piece of evidence in favour of the assumption that thematic processing takes place incrementally and independently of the verb.

In sum, there is good evidence for assuming that thematic information is processed incrementally and verb-independently, i.e., even in the face of an ambiguity, the parser attempts to maximise thematic interpretation at each point during the parse. How this may be accomplished will be the focus of the next section.

\section{Hierarchical ordering}

The discussion in the preceding sections has shown that the parser endeavours to perform thematic processing in an incremental fashion, despite the fact that thematic information is not always unambiguously determined during on-line sentence processing. Thus, it is clear that the parser must make use of certain preference strategies in the face of an ambiguity, for otherwise incrementality in the sense of the PIC could not be upheld. In order to characterise the nature of these hypothetical strategies, however, we must examine the internal structure of the thematic domain.

It is well established in the theoretical literature that thematic roles are hierarchically ordered with respect to one another (Bresnan \& Kanerva, 1989; Givón, 1984; Grimshaw, 1990; Jackendoff, 1972; Kiparsky, 1987; Primus, 1999). Primus (1999), for example, motivates this ordering on the basis of thematic dependency between the various roles, which she subsumes under the proto-roles Proto-Agent, Proto-Recipient, and ProtoPatient, on the basis of thematic features (cf. Dowty, 1991). Her version of the thematic hierarchy is shown in (4).

(4) Thematic Hierarchy (Primus, 1999, p. 3)

$\begin{array}{llll}\begin{array}{l}\text { Proto-Agent } \\ \text { agent }\end{array} & \begin{array}{l}\text { Proto-Recipient } \\ \text { recipient }\end{array} & > & \begin{array}{l}\text { Proto-Patient } \\ \text { patient }\end{array} \\ \text { causer } & \text { addressee } & \text { causee } \\ \text { experiencer } & \text { benefactive } & \text { stimulus } \\ \text { possessor } & & \text { possessed }\end{array}$


With regard to the hierarchising notion of thematic dependency, Primus assumes, following Dowty (1991), that "if one participant of a predicate is causally affected, the predicate necessarily selects a causer as another participant" (Primus, 1999, p. 52). Thus, the presence of a Proto-Patient argument entails the presence of a Proto-Agent or -Recipient. Because the notion of thematic dependency is a semantic property, it should not vary across languages and the thematic hierarchy is therefore assumed to be universal.

Let us now return to the question of how thematic preferences arise in light of these observations about the structuring of thematic information. Essentially, it appears to make little sense to assume that thematic incrementality results in individual thematic role labels being assigned to single arguments, since (a) there is no agreement about the status of these individual labels even from a theoretical point of view (cf. Dowty, 1991), and (b) distinguishing between, say, AgEnt and CAUSER appears to be more of a semantic issue and can really only be undertaken with any confidence with the processing of the verb. The advantage of using protoroles is that they abstract away from individual thematic role labels and rather focus upon the hierarchical thematic ordering between sentential arguments (Primus, 1999), which is, essentially, what the thematic representation of a sentence must provide. Thus, an incremental protorole assignment would establish for each argument whether this argument is the thematically highest of the sentential arguments (Proto-Agent), thematically lowest (Proto-Patient) or in between these two (ProtoRecipient). By contrast, such an assignment need not involve making a commitment with regard to the exact role that the argument in question plays in the event denoted by the verb, since this event-specific information may then be spelled out when the verb is processed (cf. Van Valin \& La Polla, 1997).

In this way, we arrive at the proposal that thematic preferences may apply not to single arguments, but rather subserve a hierarchising purpose between arguments. This may be illustrated on the basis of the German subordinate clause in (5).

(5) ... dass der Gärtner den Einsiedler befragte.

$\ldots$ that the $\mathrm{NOM}_{\mathrm{N}}$ gardener the $\mathrm{ACC}_{\mathrm{A}}$ hermit questioned

'. . . that the gardener questioned the hermit.'

In (5), both arguments precede the verb, thus making the thematic grid of the verb available only at the last possible point during parsing. In accordance with the incremental nature of thematic processing established above (and the observation that incremental parsing also holds in headfinal structures; Bader \& Lasser, 1994; Kamide \& Mitchell, 1999), it would make sense for the arguments in (5) to be at least hierarchically ordered 
with respect to each other even before the verb is encountered. In this way, "who is doing something to whom" is already clear, the exact nature of the something then being more closely specified at the clause-final position. This intuitively plausible strategy is supported by the experimental findings for German double case violations discussed above (see example 3): the presence of an N400 at the position of the second NP when this is identically case marked to the first NP indicates that it is the inability to thematically hierarchise between the arguments that gives rise to the violation.

These experimental findings also provide evidence with respect to how thematic preferences may be established. Theoretical proposals (Primus, 1999) and the experimental findings on double case ungrammaticalities discussed above indicate that morphological case marking plays a crucial role in the establishment of thematic relations between arguments. Thus, in (3a) the thematic violation is detected on the basis of case marking alone, i.e., without the verb having been processed. The consequence of this account is, of course, that thematic hierarchising should take place on the basis of morphological case (in case marking languages such as German). We will adopt this last proposal as a working hypothesis.

\section{Summary}

To summarise the discussion so far, we have put forward that thematic information is potentially ambiguous, processed incrementally and suitably structured for preference strategies to apply. With regard to the last of these points, we have suggested that thematic preferences operate in terms of hierarchising processes which draw upon morphological case information. It therefore appears that thematic information fulfils all the prerequisites that are necessary for reanalysis effects to be experimentally observable. In the next section, we will discuss how the hypothesis that thematic reanalyses exist can be experimentally tested.

\section{THEMATIC REANALYSIS AND PSYCHOLOGICAL VERBS}

A thematic reanalysis should be necessary when the hierarchical thematic ordering that has been established between sentential arguments must be revised, i.e., when a reassignment of a higher or lower thematic role to the arguments becomes necessary. Such effects may be induced by employing so-called 'psychological verbs'.

The term 'psychological verbs' (henceforth: 'psych-verbs') refers to the class of verbs for which one sentential argument is attributed a state of 'experiencing' or 'perceiving' something in a way that presupposes a conscious mental state. The state of experiencing/perceiving thus described 
is usually associated with the thematic role EXPERIENCER and presupposes that the argument refers to an animate entity with the ability to experience changing mental states (i.e., the argument must usually refer to an entity that is [+human]). Within the greater class of psych-verbs, it is customary to differentiate between the so-called 'subject-experiencer' (e.g., fear) and the so-called 'object-experiencer' (e.g., frighten) verbs, the former being those in which the subject is assigned the thematic role of EXPERIENCER, whereas in the latter this role is assigned to the object. The difference between subject-experiencer and object-experiencer verbs is illustrated in (6).

(6) a. Steve fears snakes.

b. Snakes frighten Steve.

With regard to thematic relations, the examples (6a) and (6b) appear to resemble each other very closely, i.e., Steve is the participant experiencing fear, this emotion being due to snakes. However, Steve is the subject of the verb fear in (6a) and the object of the verb frighten in (6b), hence leading to the distinction between 'subject-experiencer' and 'object-experiencer' verbs.

At this point, the relevance of psych-verbs for the elicitation of thematic reanalysis effects becomes apparent. Under the assumption that thematic relations between subject and object are indeed reversed between (6a) and (6b), it should be possible to either confirm or disconfirm a preference for a particular thematic ordering between arguments in verb-final sentences. Clearly, this crucially depends on the properties of object-experiencer verbs, since it is this verb class which allows for a reversal of the hierarchical thematic relations between the arguments. Thus, in order to ensure that a reversal of thematic relations can be presupposed, we must consider the properties of object-experiencer verbs in German, the language we will be using to examine the thematic reanalysis hypothesis, more closely.

In fact, there are two classes of object-experiencer verbs in German, those subcategorising for accusative case (7a) and those subcategorising for dative case $(7 b)$ :

(7) a. Der Mönch ängstigte den Jungen.

the $_{\text {NOM }}$ monk frightened the $\mathrm{ACC}_{\text {boy }}$

'The monk frightened the boy.'

b. Der Mönch gefiel dem Jungen.

the $_{\text {NOM }}$ monk pleased the DAT $_{\text {boy }}$

'The monk pleased the boy.' 
Many researchers assume that accusative object-experiencer verbs (e.g., ängstigen, 'to frighten', in 7a) allow a causative reading in which the subject (CAUSE) is thematically higher than the object (EXPERIENCER) (Primus, 1999; Wunderlich, 1997; Fanselow, 2000). Thus, a sentence such as Der Mönch ängstigte den Jungen mit einem großen Messer ('The monk frightened the boy with a large knife') is well-formed even with the instrumental reading of the PP, which forces the subject to be an Agent.

This analysis, under which verbs such as ängstigen may be processed as agentive/causative predicates, is supported by the results of an eyetracking study reported in Scheepers, Hemforth, and Konieczny (2000). These authors examined sentences of the form in (8) in view of the question whether the subject-preference for ambiguous initial arguments in German may be influenced by the prior processing of an accusative object-experiencer verb.

(8) Vielleicht ängstigte die stille Schülerin der strenge Lehrer ein wenig,

perhaps frightened the $\mathrm{NOM}_{\mathrm{N} / \mathrm{ACC}}$ quiet pupil the $\mathrm{NOM}_{\mathrm{NO}}$ stern teacher a little

so wurde vermutet.

so was suspected

'It was suspected that the stern teacher perhaps frightened the quiet pupil a little.'

In view of the fact that word order in the German middlefield (i.e., the portion of a German sentence beginning after the finite verb in main clauses or the complementiser in embedded clauses and ending before a sentence-final verb or particle) reflects the relative thematic ordering between the arguments (Primus, 1998, 1999), sentences such as (8) should give rise to an object preference for the ambiguous initial NP if it is indeed the case that accusative object experiencers require a reversed thematic ordering between subject and object. However, Scheepers et al. found that disambiguating towards an object-initial structure gave rise to an increase in first pass reading times that was independent of the type of verb preceding the arguments. The interaction between verb type and word order, which reflected the fact that object-initial orders were less difficult for clauses with object-experiencer verbs, reached significance in regression path durations at the clause-final position only. A possible explanation of this finding is that accusative object-experiencer verbs cannot force a reversal of the hierarchical thematic ordering between arguments, since they allow for a causative (i.e., non-reversing) reading. The 'true' objectexperiencer reading, by contrast, appears to have only a modulating influence in a post-initial processing step in these verbs. 
In summary, there is both theoretical and empirical evidence to suggest that German accusative object-experiencers are problematical for an examination of thematic reanalysis in the sense described above.

In contrast to the accusative object-experiencers (and also to the English object-experiencer class), dative object-experiencer verbs in German (e.g., gefallen, 'to please', in 7b) are stative, thus excluding the possibility of assigning the non-EXPERIENCER argument the role of CAUSE. It is therefore generally assumed in the syntactic literature that this verb class requires a 'true' object experiencer reading, i.e., a reading in which the dativemarked argument is thematically higher than the nominative-marked argument (Fanselow, 2000; Primus, 1999; Wunderlich, 1997).

Hence, a starting point for eliciting thematic reanalysis effects in German is illustrated by the structures in (9).

(9) a. Ich glaube, dass der Mann dem Gärtner vertraut. I believe that the NOM $_{\text {man }}$ the DAT $_{\text {gardener trusts }}$ 'I believe that the man trusts the gardener.'

b. Ich glaube, dass der Mann dem Gärtner gefällt. I believe that the NOM $_{\text {man }}$ the DAT $_{\mathrm{DA}}$ gardener pleases 'I believe that the man is pleasing to the gardener.'

In the subject-experiencer construction in (9a), the subject of the embedded clause, der Mann, is the Proto-Agent (in traditional terms: the Experiencer) of the verb vertrauen and the object, dem Gärtner, is the Proto-Patient (the Theme or Stimulus) of the event described by this verb. In the object-experiencer construction in (9b), by contrast, the ordering of thematic relations is reversed: der Mann is the Proto-Patient and dem Gärtner the Proto-Agent. Assuming that thematic roles are hierarchically ordered (see above), the hierarchical thematic ordering of der Mann in relation to dem Gärtner is reversed between (9a) and (9b). ${ }^{1}$ Assuming further that hierarchical thematic relations are established between arguments on the basis of their morphological case marking (see above), (9b) should give rise to a thematic reanalysis in comparison with (9a), because the default relation between a nominative and a dative argument should always involve the nominative as thematically higher.

\footnotetext{
${ }^{1}$ Note that the thematic ambiguity in these sentences is therefore not an ambiguity with regard to the individual thematic roles borne by the arguments, but only with regard to the hierarchical ordering between them.
} 


\section{THE PRESENT STUDY}

\section{Experimental Design}

The present experiment will use event-related brain potentials (ERPs) to examine thematic reanalysis effects in unambiguously case marked German verb final clauses by varying the thematic structures of the clause-final verb. This manipulation of the verb's thematic structure is captured by the factor VERB (active vs. object-experiencer). Note that, rather than comparing subject-experiencer and object-experiencer dative verbs at this point, we will use dative active verbs (i.e., verbs with an Agent-Patient thematic structure in traditional terms) instead of subjectexperiencers. This is necessitated by the very low occurrence of dative subject-experiencers in German, which renders the inclusion of this verb class in an ERP experiment impossible. While the concrete thematic roles differ between subject-experiencer verbs and active verbs, the hierarchical relation between subject and object remains the same between the two verb classes and thus the essential manipulation expressed by the factor VERB is not affected.

In addition to the thematic variation, the experiment involves a manipulation of word order. While we have hypothesised that the mechanisms responsible for thematic hierarchising operate on the basis of morphological case, the thematically based ordering of the German middlefield (see above) would also lend itself to a mechanism assuming that the first argument is always thematically highest. Thus, the manipulation captured by the factor ORDER (word order; SO vs. OS) will allow us to tease apart these possible alternatives. The factors VERB and ORDER give rise to a $2 \times 2$ design, the four conditions of which are illustrated in (10).

(10) a. Active (NOM-DAT)

... dass der Priester dem Gärtner folgt und ...

$\ldots$ that the NOM priest the $_{\text {DAT }}$ gardener follows and ...

'... that the priest is following the gardener.'

b. ObjExp (NOM-DAT)

... dass der Priester dem Gärtner imponiert und ...

$\ldots$ that the $\mathrm{N}_{\mathrm{NOM}}$ priest the $\mathrm{DAT}_{\mathrm{DAT}}$ gardener impresses and ...

'... that the priest impresses the gardener.'

c. Active (DAT-NOM)

... dass dem Priester der Gärtner folgt und ...

$\ldots$ that the $\mathrm{DAT}_{\mathrm{DAT}}$ priest the $\mathrm{NOM}_{\mathrm{NOM}}$ gardener follows and ...

'... that the gardener is following the priest.' 


\section{d. ObjExp (DAT-NOM)}

... dass dem Priester der Gärtner imponiert und ...

$\ldots$ that the $\mathrm{DAT}_{\mathrm{DAT}}$ priest the $\mathrm{NOM}_{\mathrm{NOM}}$ gardener impresses and ...

'... that the gardener impresses the priest.'

\section{Hypotheses}

We will formulate our hypotheses for the experimental sentences in (10) in terms of Friederici's $(1999,2002)$ neurocognitive model of language comprehension. This model assumes that, after phonological recognition has taken place, language comprehension essentially proceeds in three stages.

The first processing stage is accomplished between c. 150 and $200 \mathrm{~ms}$ post stimulus onset. It involves word category identification and initial syntactic structure building and is reflected in the early left-anterior negativity (ELAN) component. Experimental evidence for this view is provided by studies showing that phrase structure violations elicit an ELAN (Hahne \& Friederici, 1999; Neville, Nicol, Barss, Forster \& Garrett, 1991).

The processing steps constituting stage 2 take place between c. 300 and $500 \mathrm{~ms}$ post stimulus-onset. It is assumed that the mechanisms applying at this point are responsible for lexical-semantic integration, which is reflected by the N400 (experimental evidence for this interpretation is reported, for example, in Kutas \& Hillyard, 1980, 1983; Van Petten \& Kutas, 1991), and the processing of structural/functional information, which is reflected by the LAN (for experimental evidence see Coulson, King, \& Kutas, 1998; Gunter, Friederici, \& Schriefers, 2000; Gunter, Stowe, \& Mulder, 1997; Münte, Heinze, \& Mangun, 1993; Rösler, Friederici, Pütz, \& Hahne, 1993). While these processes apply in parallel, they are thought to engage different neural networks.

During stage 3 of processing, which takes place between approximately 600 and $900 \mathrm{~ms}$ post stimulus onset, processes of reanalysis and repair apply. These are reflected in the P600 (cf. data reported in Friederici \& Mecklinger, 1996; Gunter et al., 1997; Hagoort, Brown, \& Groothusen, 1993; Osterhout \& Holcomb, 1992, 1993; Osterhout, Holcomb, \& Swinney, 1994; Rösler et al., 1993) Such processes become necessary when the syntactic and semantic structures that were created autonomously from one another in the previous stages cannot be mapped onto one another. In this way, the fact that the P600 appears to be influenced by both syntactic and semantic factors (Gunter et al., 1997, 2000) is accounted for.

Turning now to the concrete hypotheses for the present experiment, there are three critical positions in the sentences in (10): the first NP, the 
second NP, and the verb. The predictions formulated for these positions on the basis of the model in Friederici $(1999,2002)$ will be discussed in turn.

NP1. Previous experimental results have demonstrated that the dislocation of non-pronominal object arguments in the German middlefield ('scrambling') ${ }^{2}$ elicits a fronto-central negativity between 300 and 450 ms post onset of the moved constituent (Rösler, Pechmann, Streb, Röder, \& Henninghausen, 1998; Schlesewsky, Bornkessel, \& Frisch, in press). These studies examined scrambling in sentences such as (11), in which the dative-marked determiner following the auxiliary in second position unambiguously signals a dislocated constituent.

(11) Vielleicht hat dem Ritter der König den Brief vorgelesen. perhaps had the DAT $_{\text {B }}$ knight the NOM $_{\text {king }}$ the ${ }_{\text {ACC }}$ letter read-to 'Perhaps the king has read the letter to the knight.'

In the embedded sentences used in the present experiment, however, an initial dative need not have been scrambled, as the passive construction in (12) demonstrates.

(12) ... dass dem Ritter geholfen wurde. $\ldots$ that the DAT $_{\text {knight helped was }}$

'... that the knight was helped.'

Thus, a dative following the complementiser could be the sole argument of a passivised verb, in which case it would be licensed in its base position. This possibility gives rise to the prediction that, in contrast to the previous experiments examining scrambling, the present experiment should not give rise to the characteristic 'scrambling negativity' for initial datives, seeing that the parser should be sensitive to the second (and most likely more preferable) structural option open to it (cf. Bornkessel, Schlesewsky, \& Friederici, 2002a).

$N P$ 2. If the predictions for the first NP are correct and an initial dative argument gives rise to a passive reading, this analysis must be revised when the second (nominative) NP is encountered. The second NP in a dativenominative structure should thus elicit a reanalysis effect that reflects the restructuring of the phrase marker to form a scrambled structure. Previous results for structural revisions of this kind in complement clauses (Friederici \& Mecklinger, 1996; Friederici, Mecklinger, Spencer, Stein-

\footnotetext{
${ }^{2}$ Scrambling is defined as dislocation in the 'middlefield' (i.e., between the complementiser / finite verb and a sentence-final verb / particle) and thereby dissociated from dislocation to the sentence-initial position (e.g., topicalisation).
} 
hauer, \& Donchin, 2001; Steinhauer, Mecklinger, Friederici, \& Meyer, 1997) lead us to expect a late positivity at this point.

Verb. Assuming that a hierarchical thematic relation is established between the arguments even before verb information is available, this relation can essentially have been built up on the basis of morphological case, word order, or a combination of both types of information. In this way, we arrive at the following predictions.

If morphological case is the decisive factor with regard to thematic hierarchising, dative object-experiencer verbs should give rise to a thematic reanalysis effect in comparison to their active counterparts. Should word order also play a role, for example in terms of a strategy that always assumes the first argument to be thematically highest, thematic reanalysis effects should be observable for dative object-experiencer verbs when the word order is nominative-initial and for dative active verbs when the word order is dative-initial. Seeing that, like structural reanalysis, thematic reanalysis must consist of processes that revise hierarchical relations, we might speculatively assume that this type of operation elicits a positive deflection in the ERP. ${ }^{3}$

\section{Method}

Materials. The experimental sentences for this experiment were constructed on the basis of two verb lists, consisting of 20 items for the dative active verbs and 10 items for the dative object-experiencer verbs. The different number of verbs on each of these lists resulted from the relative rarity of the verb classes required for the experiment. As selecting 10 verbs per list in order for each verb class to be represented by an equal number of tokens would have resulted in an undesirably high number of repetitions of lexical material, lists with unequal numbers of members were used. The two lists of verbs differed neither with respect to their mean logarithmic lemma (type) frequencies according to the Celex corpus, active verbs: 1.20 (std error: 0.16); object-experiencer verbs: 1.29 (0.15), nor in terms of word length in syllables, active verbs: 2.00 (0.15); objectexperiencers: $1.88(0.18)$, or word length in letters, active verbs: 7.60 (0.50); object-experiencers: $7.25(0.47)$.

\footnotetext{
${ }^{3}$ Note that thematic reanalysis effects are predicted to elicit positivities despite the fact that double case ungrammaticalities in German, i.e., violations that appear to be thematic in nature, give rise to N400 effects. While two arguments bearing identical morphological case features give rise to a mismatch that results from the impossibility of building up a thematic relation between these arguments, the present experiment investigates a reversal of hierarchical thematic relations, i.e., a process that is very similar to the hierarchical revisions required in structural reanalyses.
} 
The verbs were combined with 80 pairs of masculine nouns, which were matched for length (2-3 syllables), to form 80 blocks of the four conditions shown in (10). The number of repetitions was kept equal for all verbs within a particular list and repeated combinations of particular active and object-experiencer verbs controlled. Finally, a matrix clause of the form in (13) was constructed for each block using a list of 80 proper names (40 male, 40 female) and 12 clause-embedding matrix verbs.

(13) Maria glaubt ... Maria believes ...

The total number of 320 experimental sentences thus constructed was divided into two sets of 160 sentences (40 per condition) such that participants always read two sentences constructed from a single set of lexical materials. The combination of conditions for these two similar sentences was varied across blocks so as to be unpredictable. The final set of experimental sentences presented to a participant thereby consisted of 160 critical sentences, which were combined with 160 filler sentences. Fillers made use of accusative verbs and either canonical or scrambled word orders in order to reduce the predictability of a scrambled vs. canonical structure at the position of NP1. The sentences were pseudorandomised with the following constraints: trials of the same condition were separated by at least three trials, trials containing identical lexical material were separated by at least ten trials, and there were maximally three trials in a row containing accusative or dative case.

After the presentation of an experimental sentence, participants were required to complete a comprehension task. This consisted of the presentation of a declarative sentence such as Der Priester folgt dem Gärtner ('The priest follows the gardener.'), for which the participant had to decide whether it correctly expressed the content of the preceding sentence or not. All sentences for the comprehension task were of the form Subject-Verb-Object. The comprehension task required the answer 'yes' equally as often as the answer 'no'. The incorrect sentences either involved a substituted first NP, a substituted second NP, or a substituted verb.

Participants. Thirty-three students from the University of Leipzig were paid for their participation in this experiment (16 females; mean age 24 years; age range from 20 to 31 years). All were right-handed, monolingual native speakers of German and had normal or corrected-to-normal vision. Twenty-six of the participants entered the final data analysis, the remaining seven having been excluded on the basis of EEG-artifacts and/or insufficient accuracy in the comprehension task (an error rate of $>40 \%$ in any one condition). 
Procedure. Each sentence was presented in a phrase-by-phrase manner (with the matrix clause being presented as a whole) in the centre of a 17 inch computer screen. The presentation of a sentence was preceded by an asterisk, which appeared for $300 \mathrm{~ms}$ followed by a pause of $300 \mathrm{~ms}$. Single word segments were presented for $450 \mathrm{~ms}$ and phrasal segments for $500 \mathrm{~ms}$ with an inter-stimulus interval of $100 \mathrm{~ms}$. The presentation of a sentence was followed by an $800 \mathrm{~ms}$ pause, after which the declarative sentence constituting the comprehension task was presented. Participants were given maximally $4000 \mathrm{~ms}$ to decide whether this sentence correctly described the content of the preceding experimental sentence by means of pressing one of two hand-held push-buttons. After an answer had been given, there was a $500 \mathrm{~ms}$ pause before an asterisk signalled the beginning of the next sentence. In the case of no answer having been given within the time limit, the participant was notified that time had run out before a 500 ms pause. Participants were asked to avoid movements and to only blink their eyes between their response to the comprehension task and the presentation of the next sentence.

The presentation of the 320 sentences constituting an experimental session was carried out in eight blocks of 40 sentences each. It was ensured that each condition occurred approximately equally often in each block. In addition to the four versions of materials, the order of blocks within a version and the assignment of the values 'correct' and 'incorrect' to the left and right push-buttons was varied between participants.

EEG recording. The EEG was recorded by means of $\mathrm{AgAgCl}-$ electrodes, which were fixed at the scalp by means of an elastic cap (Electro Cap International). Recording took place from the following electrode sites, which are labelled according to the position nomenclature proposed by the American Electroencephalographic Society (cf. Sharbrough, Chatrian, Lesser, Lüders, Nuwer, \& Picton, 1991): F7, F3, FZ, F4, F8, FC5, FCZ, FC6, T7, C3, CZ, C4, T8, CP5, CPZ, CP6, P7, P3, PZ, P4, $\mathrm{P} 8, \mathrm{PO} 3, \mathrm{POZ}, \mathrm{PO} 4, \mathrm{OZ}$. The ground electrode was positioned above the sternum. Recordings were referenced to the left mastoid, but re-referenced to linked mastoids offline. In order to control for artifacts resulting from eye movements, the electro-oculogram (EOG) was monitored by means of electrodes placed at the outer canthus of each eye for the horizontal EOG and above and below the participant's right eye for the vertical EOG. Electrode impedances were kept below $5 \mathrm{k} \Omega$.

All EEG and EOG channels were amplified using a Twente Medical Systems DC amplifier and recorded continuously with a digitisation rate of $250 \mathrm{~Hz}$. The ERPs were filtered off-line with $10 \mathrm{~Hz}$ low pass for the plots, but all statistical analyses were computed on non-filtered data. 
Data analysis. For the behavioural data, error rates and reaction times were calculated for each condition. Incorrectly answered trials were excluded from the reaction time analysis.

For each of the three critical positions in the experimental sentences, the EEG data per condition per participant were averaged from the onset of the stimulus item to $1500 \mathrm{~ms}$ post onset, before grand-averages were computed over all participants. Averaging took place relative to a baseline interval from -200 to $0 \mathrm{~ms}$ before the onset of the word or phrase in question (i.e. NP1, NP2, or the verb).

Trials for which the comprehension task was not performed correctly were excluded from the averaging procedure, as were trials containing ocular, amplifier-saturation or other artifacts (the EOG rejection criterion was $40 \mu \mathrm{V}$ ).

For the statistical analysis of the ERP data, repeated measures analyses of variance (ANOVAs) were calculated for mean amplitude values per time window per condition. Time windows were chosen on the basis of previous studies and visual inspection of the data. The statistical analysis was carried out in a hierarchical manner, i.e., only significant interactions $(p<.05)$ were resolved. Additionally, no main effects of or interactions between topographical factors will be reported. In order to avoid excessive Type I errors due to violations of sphericity, we applied the correction of Huynh \& Feldt (1970) when the analysis involved factors with more than one degree of freedom in the numerator.

Topographical factors were chosen as follows: for the midline electrodes, the factor Electrode (ELEC) with the seven electrodes FZ, FCZ, CZ, CPZ, $\mathrm{PZ}, \mathrm{POZ}$ and $\mathrm{OZ}$ as levels; for the lateral electrodes, the factors Hemisphere (Hemi; left vs. right) and REGION (anterior, central, posterior). Crossing the two factors for the lateral electrodes resulted in the following six regions of interest (ROIs): left-anterior: F7, F3, FC5; left-central: T7, C3, CP5; left-posterior: $\mathrm{P} 7, \mathrm{P} 3, \mathrm{PO} 3$; right-anterior: F8, F4, FC6; right-central: $\mathrm{T} 8, \mathrm{C} 4, \mathrm{CP} 6$; right-posterior: $\mathrm{P} 8, \mathrm{P} 4, \mathrm{PO} 4$.

\section{Results}

Behavioural data. With regard to error rates, a repeated measures ANOVA revealed a main effect of Order, $F(1,25)=8.87, p<.01$, with object-initial structures giving rise to a higher error rate $(14.71 \%)$ than their subject-initial counterparts $(10.63 \%)$. The analysis of the reaction times also revealed a main effect of Order, $F(1,25)=13.02, p<.002$, as well as a marginal main effect of Verb, $F(1,25)=3.99, p<.06$. Reaction times were longer for object-initial (1561 ms) than subject-initial $(1512 \mathrm{~ms})$ structures and for structures involving object-experiencer verbs $(1552 \mathrm{~ms})$ in contrast to their active counterparts $(1520 \mathrm{~ms})$. 
ERP data. Figure 1 shows grand averages for dative-initial vs. nominative-initial structures at the position of the first NP. Descriptively, the two conditions do not appear to differ from one another. This was confirmed by the statistical analysis, which revealed no reliable effects in the comparison of these two conditions up to the onset of the second NP.

The critical comparison for the second NP, i.e., dative-nominative vs. nominative-dative word orders, is shown in Figure 2. Here, dativenominative structures show an early positivity in comparison to their nominative-dative counterparts.

For the statistical analysis, a time window from $200-350 \mathrm{~ms}$ post onset of the noun phrase was chosen. The global analysis of the lateral electrodes revealed a significant interaction Order $\times$ Region, $F(2,50)=7.04, p<$ .01. Planned comparisons for each of the six lateral ROIs revealed significant main effects of Order in the left-posterior, $F(1,25)=4.53, p<$ .05 , and right-posterior, $F(1,25)=5.08, p<.04$, regions. In both cases, the ERPs elicited by dative-nominative word orders were more positive those elicited by their nominative-dative counterparts.
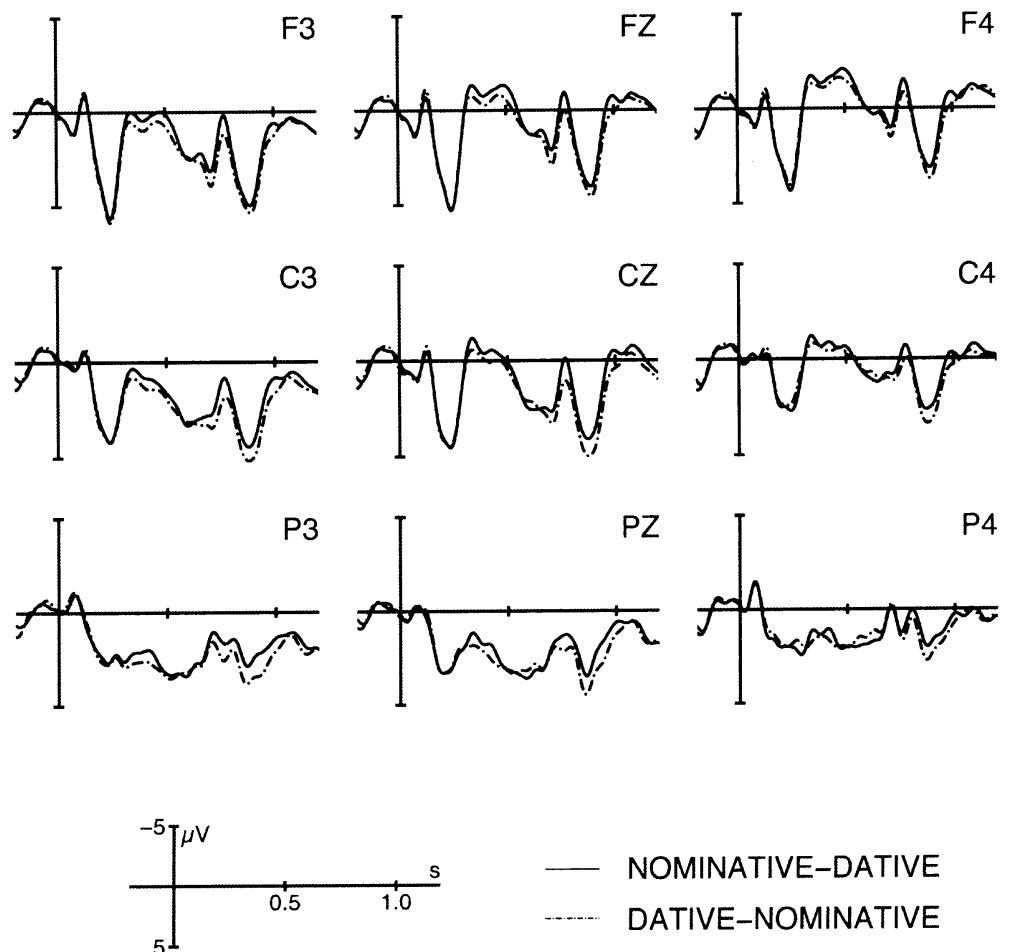

Figure 1. Grand average ERPs elicited by the first NP (onset at the vertical line) for dativeinitial vs. nominative-initial structures. Negativity is plotted upwards. 

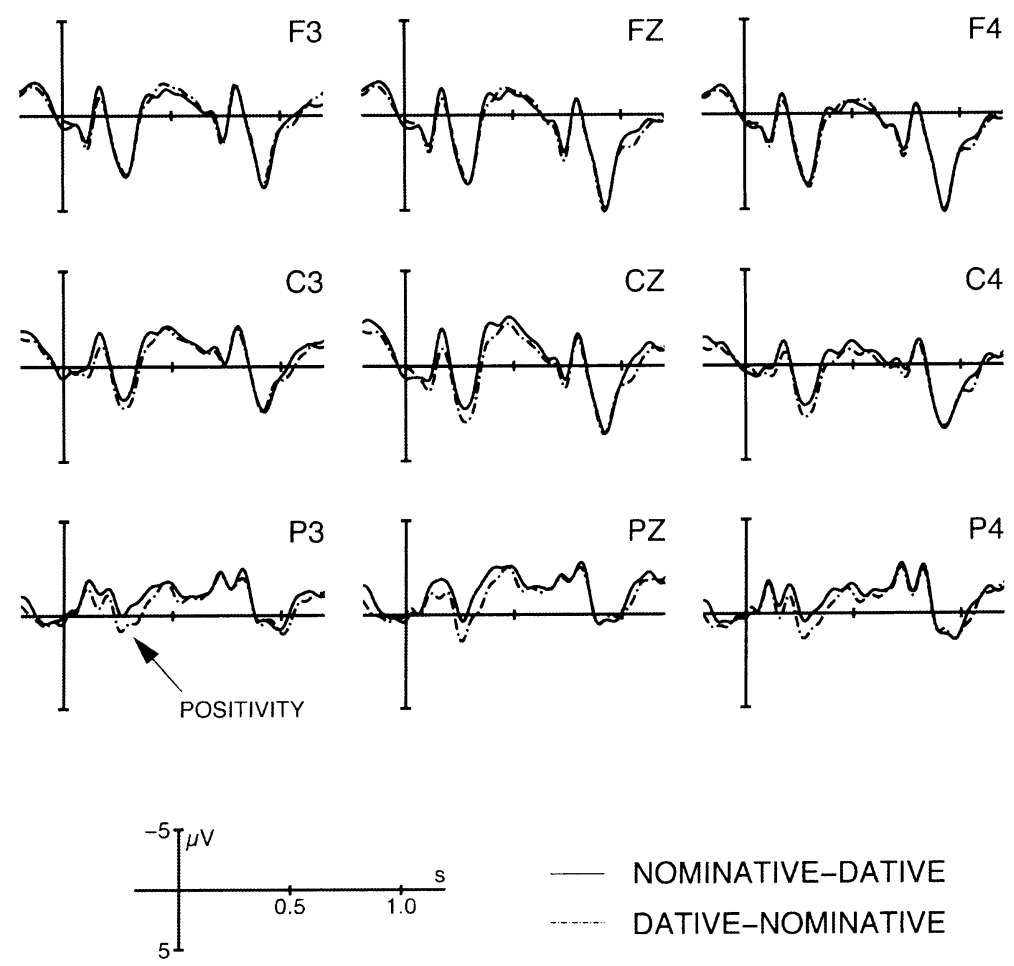

- NOMINATIVE-DATIVE

Figure 2. Grand average ERPs elicited by the second NP (onset at the vertical line) for dative-nominative vs. nominative-dative word orders. Negativity is plotted upwards.

The global analysis for the midline electrodes showed an interaction Elec $\times$ Order, $F(6,150)=5.08, p<.02$. Resolving this interaction by Elec showed significant effects of Order at electrodes POZ, $F(1,25)=5.09, p$ $<.04$, and OZ, $F(1,25)=5.24, p<.04$, as well as a marginal effect of Order at PZ, $F(1,25)=3.69, p<.07$. Again, these differences were due to a positivity in the dative-nominative condition.

In order to ensure that the effects at the position of NP2 are not in fact late components attributable to the processing of NP1 (see the Discussion section), we conducted a further analysis for the time window from 50-200 ms post onset of NP2. This analysis revealed no significant main effects of or interactions with the factor Order (midline electrodes: all $F<1$; lateral electrodes: all $F<1.85$, all $p>.187$ ).

Figure 3 shows grand average ERPs at the position of the verb. Descriptively, the conditions including active verbs appear to differ from those including object-experiencers in that the latter are more positive than the former between 300 and 600 ms post onset. 

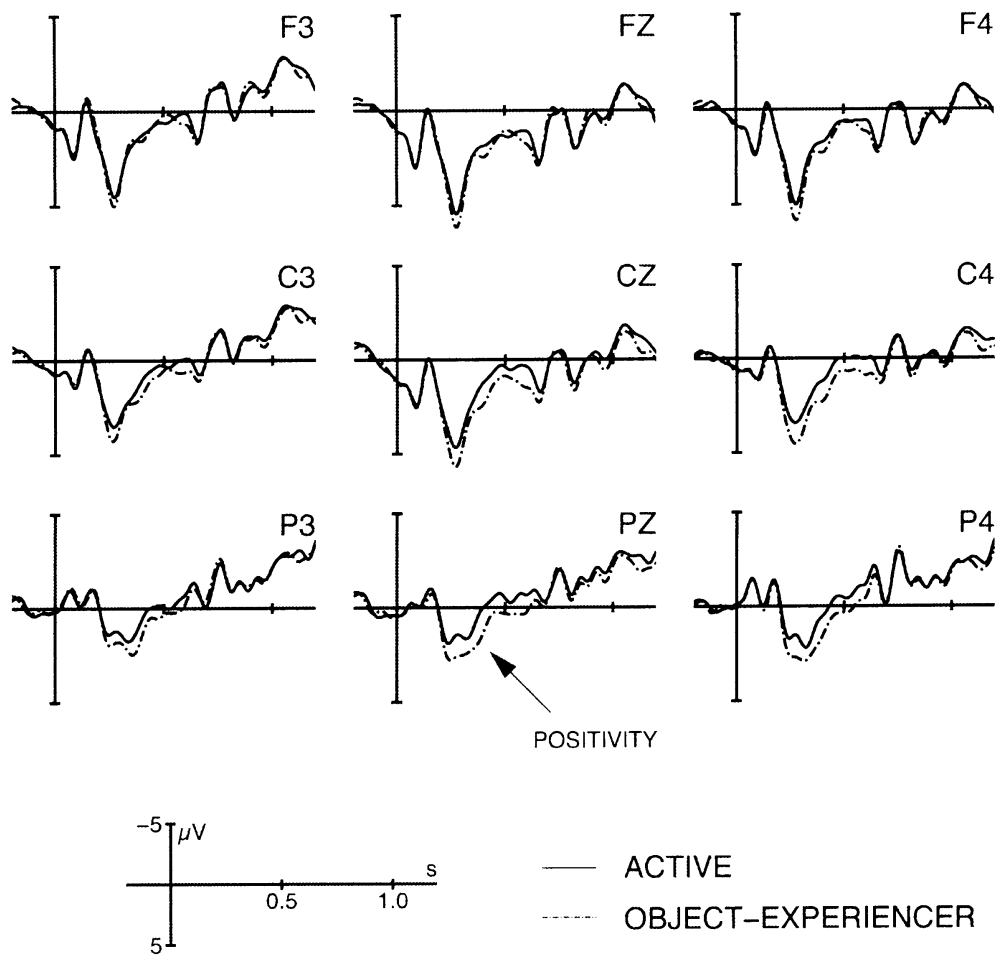

Figure 3. Grand average ERPs elicited by the verb for (dative) active verbs vs. (dative) object-experiencer verbs (onset at the vertical line). Negativity is plotted upwards.

The global statistical analysis of the lateral electrodes for the time window 300-600 ms revealed a significant main effect of Verb, $F(1,25)=$ $5.36, p<.03$, object-experiencer verbs more positive than active verbs, as well as a marginal interaction of Order $\times$ Hemi $\times$ Region, $F(1,25)=3.39$, $p<.07$. Resolving this interaction by ROIs showed no main effects of Order in any of the regions (all $F<1.28$ ).

The midline electrodes also showed a main effect of Verb, $F(1,25)=$ $11.92, p<.01$, which was due to a positivity for object-experiencer in comparison to active verbs.

\section{DISCUSSION}

We have presented an ERP experiment examining the hypothesis that structure-independent (viz. thematic) reanalysis effects exist. Essentially, our data show three interesting results: (a) in embedded German dass ('that')-clauses, initial dative NPs do not give rise to a negativity; (b) in dative-nominative structures, the second NP gives rise to an early parietal 
positivity (between 200 and $350 \mathrm{~ms}$ post onset); (c) at the position of the sentence-final verb, dative object-experiencer verbs elicit an early parietal positivity (300-600 ms post onset) independently of word order. In the following, we will firstly turn to our main point of interest in this paper, namely whether the data from the present experiment constitute evidence for the existence of thematic reanalysis effects, before discussing the other effects.

At the position of the clause-final verb, we found an early positivity for dative object-experiencer verbs in comparison with their active counterparts. Crucially, this effect was independent of word order, i.e., of whether the argument order of the clause was subject-before-object or objectbefore-subject. Thus, the early positivity cannot be a reflection of changes affecting the syntactic structure of the sentence, but must rather be seen as arising exclusively as a result of the thematic manipulation at the position of the verb (active vs. object-experiencer verbs). Additionally, a further study using the same verbs and a similar design to the present experiment has replicated the early positivity observed here for unambiguously case marked verb-final sentences, while showing that no such effect obtains in ambiguously case-marked sentences (Bornkessel, Schlesewsky, \& Friederici, 2002b). These findings clearly indicate that the early positivity does not result from a simple, lexical difference between the two verb classes. Rather, recall that the two verb classes used in the present experiment differed with respect to the hierarchical thematic ordering between the sentential arguments, i.e., active verbs require a nominative-dative thematic ordering and object-experiencer verbs a dative-nominative thematic ordering. In this way, the positivity for object experiencer verbs in unambiguously case marked sentences indicates that the arguments must have been thematically hierarchised with respect to one another before the verb was encountered, therefore requiring a reversal of hierarchical thematic relations when an object-experiencer verb is processed. Since these changes involve altering hierarchical relations and are therefore somewhat similar to structural reanalyses, we will refer to them as thematic reanalysis.

In this way, the data support the hypothesis that, in German, hierarchical thematic relations are established even before the verb is encountered. Since a positivity was observed for all object-experiencer verbs in contrast to their active counterparts, the present findings suggest that thematic hierarchising of the arguments takes place on the basis of their morphological case information (Bornkessel et al., 2002b). Thus, at the position of the second NP in the present experimental sentences, both arguments are thematically hierarchised according to their case features. If this hierarchical ordering is confirmed by the verb, processing may proceed without problems. However, should the verb require a 
reversal of the thematic ordering between the arguments, a thematic reanalysis results.

An important consequence of the observation that sentential arguments in German are thematically hierarchised with respect to one another before the verb is encountered is that the costs of this hierarchising process should also be visible at positions prior to the verb under certain circumstances. In fact, the data pattern observed at the positions of the first and second NP in the present experiment appears to support such a view. In other words, both the absence of an effect for initial datives as well as the early positivity at the position of NP2 in dative-nominative structures indicate that thematic hierarchising is taking place at these points. We will give a detailed account of how this might be envisaged in the following.

First, recall from above that morphological case has been assumed to reflect the thematic relations between the arguments of a sentence (Primus, 1999). In this way, when a case marked argument is encountered, it will activate a cluster of thematic properties which are potentially compatible with the case borne by the NP. Thus, a dative will activate the features $\left[+\right.$ control$^{4}{ }^{4}+$ sentience, etc.], features which are compatible with the Proto-Agent role. In accordance with the observation that the German middlefield is organised in terms of the thematic structure of a sentence (Primus, 1998, 1999), it is plausible to assume that the left-most argument encountered in the middlefield will be associated with the Proto-Agent role if this is at all possible. Therefore, an initial dative will be associated with the Proto-Agent role (while, incidentally, an initial accusative, which lacks features such as [+control] and [+sentience] cannot be thus associated). In this way, the absence of an effect for initial dative-marked arguments is straightforwardly accounted for: since these arguments are potential Proto-Agents they do not give rise to thematically based processing difficulties at this point.

At this point the question arises of what happens when the Proto-Agent association for an initial dative must be revised. In fact, this is exactly what must take place in the experimental sentences used here, since the nominative-bearing argument following an initial dative activates thematic features including [+control, +causation, +sentience, etc.], thereby outranking the dative argument with respect to Proto-Agent properties. In this way, the early positivity on the second NP of dative-nominative structures might also reflect thematic reanalysis processes in the form of a forced revision of the Proto-Agent association for the dative argument.

However, at first glance it may appear puzzling that the Proto-Agent interpretation initially assigned to the dative should be revised when a

\footnotetext{
${ }^{4}$ For a motivation of the assumption that the dative allows [+control], see Wegener (1985) and Primus (1999).
} 
nominative argument appears, seeing that there are constructions compatible with a dative Proto-Agent and a nominative Proto-Patient (viz. the dative object-experiencer constructions examined in this paper). In this regard, one may speculate that the [+animate] status of the NPs used in the experimental material of the present experiment may have played a crucial role: whenever an animate nominative argument is present in a sentence, the need to interpret this argument as a Proto-Agent is too strong to be overridden by other considerations (Frisch \& Schlesewsky, 2001; Primus, 1999; Tomlin, 1986; Zubin \& Köpke, 1985). In this way, one might informally classify such animate nominatives as ideal ProtoAgents'.5

This leads us to a further interesting point that arises from the consideration of the present data: the observation that thematic relations can be established without drawing upon word order information when arguments are unambiguously case marked implies that, with regard to the interpretation of the arguments alone, there may be no need for a structural reanalysis at the position of the second NP in sentences with a dative-nominative word order, but only for a thematic reanalysis. ${ }^{6}$ This observation is compatible with the data pattern of the present experiment: rather than a late positivity, i.e., the component observed in all previous studies examining syntactic reanalyses towards an object-initial structure in the middlefield (Friederici \& Mecklinger, 1996; Friederici et al., 2001; Steinhauer et al., 1997), we found an early positivity at the position of the second NP. These findings are more straightforwardly accounted for by assuming that a thematic reanalysis, rather than a syntactic reanalysis is initiated at this position, since the component observed here has been shown to be associated with thematic reanalysis by the ERP patterns at the position of the verb in the present study and in Bornkessel et al. (2002b). In this way, it appears that two case marked arguments may be placed in a hierarchical thematic ordering without requiring word order information /

\footnotetext{
${ }^{5}$ Again, this is reflected by preferences with regard to unmarked word order. While the word order for dative object-experiencer verbs with an animate dative and an inanimate nominative is clearly dative-nominative, the relative ordering between two animate arguments is much less clear.

${ }^{6} \mathrm{We}$ do not mean to suggest by this that unambiguously case marked sentences in German do not require syntactic structure at all. Thus the calculation of scope and information structural relations, for example, appears to be structure dependent. However, these types of information constitute global properties of a sentence and should therefore perhaps be envisaged as being calculated sentence-finally, rather than incrementally. Thus, while we cannot exclude on the basis of the present data that structural relations pertaining to arguments are computed in parallel to the case-based thematic relations discussed here, our data-especially in combination with the data in Bornkessel et al. (2002b) - presently provide no evidence in favour of such an assumption.
} 
information about the thematic structure of the verb. Case marking languages such as German therefore seem to allow for a processing route that determines thematic (proto-)role assignment (and, thereby, incremental sentence interpretation) independently of hierarchical syntactic information.

Before turning to a more detailed characterisation of such non-syntactic processing mechanisms, however, it is important to clarify why an effect with an onset latency of $200 \mathrm{~ms}$ should, in fact, be attributed to processing associated with NP2 rather than with NP1 (with respect to which its onset latency would be $800 \mathrm{~ms}$ ). First, recall that the statistical analysis of the time window from 50 to $200 \mathrm{~ms}$ post onset of NP2 revealed no significant effects, thus allowing us to assume that the onset of the effect is truly at 200 $\mathrm{ms}$ and not earlier. We have hypothesised that the early positivity reflects the thematic reanalysis of NP1, albeit elicited by the processing of NP2, and, importantly, such an operation can be initiated via quite basic features of NP2, namely nominative case marking and animacy. Both of these information types are assumed to be available as early as $200 \mathrm{~ms}$ post critical word onset onwards (i.e., in phase 2 of comprehension) in Friederici's $(1999,2002)$ neurocognitive model of language comprehension. Moreover, it has been shown by means of ERP and magnetoencephalographic (MEG) studies that lexical/conceptual/semantic information is already available at latencies even shorter than $200 \mathrm{~ms}$ post critical stimulus onset (Brown, van Berkum, \& Hagoort, 2000; Pulvermüller, Assadollahi, \& Elbert, 2001; Skrandies, 1998). There is also direct empirical support for assuming that a thematic reanalysis may be initiated from $200 \mathrm{~ms}$ onwards: the early positivity for object-experiencer verbs in unambiguously case marked structures in Bornkessel et al. (2002b), i.e., the replication of the verb effect reported here, reaches significance in a time window from 200 to $600 \mathrm{~ms}$. In this way, it appears plausible to assume that the positivity may indeed reflect a reanalysis of the thematic properties of NP1 elicited by NP2.

If, by contrast, the positivity were to reflect the processing of NP1, the simplest interpretation of such an effect would be in terms of processing difficulties elicited by an object at the left edge of the German middlefield. However, this interpretation is not compatible with previous results: recall from the Hypotheses section that Rösler et al. (1998), Schlesewsky et al. (in press), and Bornkessel et al. (2002a) all report fronto-central negativities in the time range of $300-450 \mathrm{~ms}$ post onset of the initial argument. This is the case for both accusatives and datives in the experiments reported by Rösler et al. (1998) and Schlesewsky et al. (in press), but recall that, in contrast to the present experiment and that of Bornkessel et al. (2002a), these experiments used constructions that rule out a canonical left edge positioning of a dative (e.g., in a passive 
construction). Thus, a positivity for an initial dative in the middlefield cannot be straightforwardly accounted for.

If, however, the effect observed here was in fact a positivity for clausemedial word order variations elicited by the processing of NP1, the onset latency of this effect would be considerably later than that of typical late positivity (P600) effects. Hence, is there evidence for assuming that the onset of this component is latency-shifted (to $800 \mathrm{~ms}$ ) in comparison with typical P600 effects (onsets at 500-600 ms), for example by the phrase-byphrase presentation format? The three studies cited above again provide important evidence in this regard, since Rösler et al. (1998) and Schlesewsky et al. (in press) used a word-by-word presentation mode, whereas Bornkessel et al. (2002a) used a phrase-by-phrase presentation mode. Importantly, whereas there appear to be topographical differences between the effect elicited by an object determiner only (Rösler et al., 1998; Schlesewsky et al., in press) and an entire object NP (Bornkessel et al., 2002a), the latency of the negativity in question remains similar, i.e., the effect reaches significance in a time window from $300 \mathrm{~ms}$ onwards. Hence, there is no evidence within the domain of word order variations that a phrase-by-phrase presentation mode leads to a delay of the latency of the component. These assumptions are supported by further studies. Frisch \& Schlesewsky (2001), for example, report both N400 and P600 effects within 'normal' time windows (onsets at 300 and $600 \mathrm{~ms}$, respectively) at the position of a noun phrase eliciting an ungrammaticality, and Frisch, Schlesewsky, Saddy, and Alpermann (2002) report a reanalysis P600 with an onset at $600 \mathrm{~ms}$ that is elicited by an entire noun phrase. Thus, a latency shift on the basis of the greater information intake required by an entire noun phrase appears quite unprecedented and, therefore, relative to the onset of NP1, the onset of the positivity in our experiment lies considerably beyond those typically reported for P600 effects in the literature. In this way, evidence from previous studies indicates (a) that the positivity may plausibly reflect NP2 processing in spite of its short latency, and (b) that interpreting this component as reflecting NP2 processing appears the most parsimonious option in light of the overall data pattern.

Let us now return to the question of how a processing mechanism that accomplishes incremental sentence interpretation independently of hierarchical syntactic information might be envisaged. Essentially, the processing behaviour observed in the present experiment may be accounted for by means of the following thematic processing principles (cf. Bornkessel (2002) for a more detailed discussion).

(i) The first argument is assigned the Proto-Agent role if this is at all possible. 
(ii) Any two arguments must be hierarchically ordered with regard to one another.

(iii) An animate nominative-marked argument is assigned the ProtoAgent role unless this is expressly prohibited (by verb-specific information).

Whereas principles (i) and (ii) might be considered cross-linguistically applicable, principle (iii) may be language-specific. Principle (iii) is well motivated for German, since in this language only animate nominativemarked arguments may express Proto-Agents with ideal control over the situation/event described by the verb (Primus, 1999). Furthermore, it has been observed that similar dependencies to those expressed by this principle hold in multiple wh-questions in Bulgarian (Billings \& Rudin, 1996), thus suggesting a wider scope of applicability. Crucially, we assume that the applicability of these principles is dependent on the presence of unambiguous morphological case marking, i.e., they should only find application in case marking languages and, moreover, even in these languages only in unambiguously case marked sentences. From this perspective, unambiguous morphological case marking could tentatively be considered a 'shortcut' to sentence-level interpretation.

Finally, in view of the fact that the data pattern of the present experiment revealed two early positivies (which we have interpreted in terms of thematic reanalysis), we shall now examine how these effects may be accommodated within the typology of language-related ERP components. In fact, early positivities have been reported for reanalyses in German relative clauses such as (14) (Mecklinger, Schriefers, Steinhauer, \& Friederici, 1995; Steinhauer et al., 1997; Friederici, Steinhauer, Mecklinger, \& Meyer, 1998).

(14) Das ist die Direktorin, die die Sekretärinnen gesehen haben. this is the director who ${ }_{\mathrm{NOM} / \mathrm{ACC}}$ the $\mathrm{NOM}_{\mathrm{N} / \mathrm{ACC}}$ secretaries seen have 'This is the director whom the secretaries saw.'

The relative clause in (14) is ambiguous between a subject- and an objectrelative reading until the final auxiliary is processed. At this position, a posterior positivity with a peak latency of $345 \mathrm{~ms}$ (P345) was observed between 300 and $400 \mathrm{~ms}$ post onset of auxiliaries disambiguating the sentence towards an object-initial order. Thus, this component is very similar to the early positivities observed in the present experiment in terms of both latency and topography. With regard to the interpretation of this component and its relation to the P600, Friederici (1998) proposes that the P345 and the P600 reflect two steps in the greater reanalysis process, namely diagnosis (Fodor \& Inoue, 1994) and (structural) reanalysis, respectively. This proposal is motivated by the fact that a reanalysis in 
complement clauses (which gives rise to a late positivity) requires a restructuring of the phrase marker, while this is not the case for reanalyses in relative clauses (where only a reassignment of arguments to traces is necessary). Friederici et al. (2001) provide further evidence for this approach by means of a spatio-temporal principal component analysis (PCA) of the relative- and complement-clause data, which revealed that the late positivity in the complement clauses actually consists of two subcomponents, one of which is also observable as the early positivity elicited by relative clauses. Under this approach, the P345 is therefore a subcomponent of the positive component complex generally referred to as 'P600', which, however, is independently observable only under certain circumstances.

Interestingly, Friederici's (1998) proposal that the P345 reflects diagnosis and the thematic reanalysis account of the early positivity observed here show an interesting parallel. In both cases, early positive deflections in the ERP are interpreted as distinct from components reflecting alterations to the syntactic structure of a sentence, while the processes thought to be reflected in these components crucially refer to hierarchical relations. Thus, while we have argued that thematic reanalysis is analogous to (but independent of) structural reanalysis, since it applies to hierarchically structured information, a diagnosis of the need to structurally reanalyse also does not involve making alterations to syntactic structure, but nevertheless requires reference to hierarchical structure if it is to be successfully carried out. While the data presently available do not allow us to characterize the relation between these early positive effects (i.e., whether they have a common source or not), this would appear to constitute a fruitful goal for further research.

\section{CONCLUSION}

By means of a study using event-related brain potentials, we have presented experimental evidence for the existence of syntax-independent reanalysis effects, namely thematic reanalysis effects. Furthermore, our data suggest that, in case marking languages such as German, a hierarchical thematic ordering is established between sentential arguments. This finding supports proposals assuming that morphological case reflects the thematic relations between the arguments.

The mechanisms responsible for thematic hierarchising appear to operate solely on the basis of morphological information (i.e., case marking), since they apply independently of word order and verb information. Thus, case-marking languages apparently require a processing route that draws exclusively upon morphological marking. In light of these findings, we conclude that, in languages such as German, the role of 
structure-independent information is crucial both in reanalysis and during first-pass parsing.

\section{REFERENCES}

Bader, M., \& Lasser, I. (1994). German verb-final clauses and sentence processing: Evidence for immediate attachment. In C. Clifton, L. Frazier, \& K. Rayner (Eds.), Perspectives on sentence processing (pp. 225-242). Hillsdale, NJ: Lawrence Erlbaum Associates Inc.

beim Graben, P., Saddy, J.D., Schlesewsky, M., \& Kurths, J. (2000). Symbolic dynamics of event-related brain potentials. Physical Review E, 62, 5518-5541.

Billings, L., \& Rudin, C. (1996). Optimality and superiority: A new approach to overt multiple wh-ordering. In J. Toman (Ed.), Proceedings of the Annual Workshop on Formal Approaches to Slavic Linguistics. The College Park Meeting 1994 [FASL 3] (pp. 35-60). Ann Arbor: Michigan Slavic Publications.

Bornkessel, I. (2002). The argument-dependency model: A neurocognitive approach to incremental interpretation. MPI-Series in Cognitive Neuroscience, 28.

Bornkessel, I., Schlesewsky, M., \& Friederici, A.D. (2002a). Grammar overrides frequency: Evidence from the online processing of flexible word order. Cognition, 85, B21-B30.

Bornkessel, I., Schlesewsky, M., \& Friederici, A.D. (2002b). Beyond syntax: Language-related positivities reflect the revision of hierarchies. NeuroReport, 13, 361-364.

Bresnan, J., \& Kanerva, J.M. (1989). Locative inversion in Chichewa: A case study of factorization in grammar. Linguistic Inquiry, 20, 1-50.

Brown, C., van Berkum, J.J.A., \& Hagoort, P. (2000). Discourse before gender: an eventrelated brain potential study on the interplay of semantic and syntactic information during spoken language understanding. Journal of Psycholinguistic Research, 29, 53-68.

Coulson, S., King, J., \& Kutas, M. (1998). Expect the unexpected: Event-related brain response to morphosyntactic violations. Language and Cognitive Processes, 13, 21-58.

Crocker, M.W. (1994). On the nature of the principle-based sentence processor. In C. Clifton, L. Frazier, \& K. Rayner (Eds.), Perspectives on sentence processing (pp. 245-266). Hillsdale, NJ: Lawrence Erlbaum Associates Inc.

Dowty, D. (1991). Thematic proto-roles and argument selection. Language, 67, 547-619.

Fanselow, G. (2000). Optimal exceptions. In B. Stiebels, \& D. Wunderlich (Eds.), Lexicon in focus (pp. 173-209). Berlin: Akademie Verlag.

Fodor, J.D., \& Inoue, A. (1994). The diagnosis and cure of garden paths. Journal of Psycholinguistic Research, 23, 405-432.

Friederici, A.D. (1998). Diagnosis and reanalysis: Two processing steps the brain may differentiate. In J.D. Fodor. \& F. Ferreira (Eds.), Reanalysis in sentence processing (pp. 177-200). Dordrecht: Kluwer Academic Publishers.

Friederici, A.D. (1999). The neurobiology of language processing. In A.D. Friederici (Ed.), Language comprehension: A biological perspective (pp. 265-304). Berlin: Springer.

Friederici, A.D. (2002). Towards a neural basis of auditory sentence processing. Trends in Cognitive Sciences, 6, 78-84.

Friederici, A.D., \& Mecklinger, A. (1996). Syntactic parsing as revealed by brain responses: First pass and second pass parsing processes. Journal of Psycholinguistic Research, 25, 157 176.

Friederici, A.D., Mecklinger, A., Spencer, K.M., Steinhauer, K., \& Donchin, E. (2001). Syntactic parsing preferences and their on-line revisions: A spatio-temporal analysis of event-related brain potentials. Cognitive Brain Research, 11, 305-323.

Friederici, A.D., Steinhauer, K., Mecklinger, A., \& Meyer, M. (1998). Working memory constraints on syntactic ambiguity resolution as revealed by electrical brain responses. Biological Psychology, 47, 193-221. 
Frisch, S. (2000). Verb-Argument-Struktur, Kasus und thematische Interpretation beim Sprachverstehen. MPI-Series in Cognitive Neuroscience, 12.

Frisch, S., \& Schlesewsky, M. (2001). The N400 reflects problems of thematic hierarchizing. NeuroReport, 12, 3391-3394.

Frisch, S., Schlesewsky, M., Saddy, D., \& Alpermann, A. (2002). The P600 as an indicator of syntactic ambiguity. Cognition, 85, B83-B92.

Givón, T. (1984). Syntax: A functional-typological introduction. Amsterdam: John Benjamins.

Grimshaw, J. (1990). Argument structure. Cambridge, MA: MIT Press.

Gunter, T.C., Stowe, L.A., \& Mulder, G. (1997). When syntax meets semantics. Psychophysiology, 34, 660-676.

Gunter, T.C., Friederici, A.D., \& Schriefers, H. (2000). Syntactic gender and semantic expectancy: ERPs reveal early autonomy and late interaction. Journal of Cognitive Neuroscience, 12, 556-568.

Hagoort, P., Brown, C., \& Groothusen, J. (1993). The syntactic positive shift (SPS) as an ERP measure of syntactic processing. Language and Cognitive Processes, 8, 439-483.

Hahne, A., \& Friederici, A.D. (1999). Electrophysiological evidence for two steps in syntactic analysis: Early automatic and late controlled processes. Journal of Cognitive Neuroscience, 11, 194-205.

Huynh, H., \& Feldt, L.S. (1970). Conditions under which the mean square ratios in repeated measurement designs have exact F-distributions. Journal of the American Statistical Association, 65, 1582-1589.

Jackendoff, R.S. (1972). Semantic interpretation in generative grammar. Cambridge, MA: MIT Press.

Kamide, Y., \& Mitchell, D.C. (1999). Incremental pre-head attachment in Japanese parsing. Language and Cognitive Processes, 14, 631-662.

Kiparsky, P. (1987). Morphology and grammatical relations. Unpublished manuscript, Stanford University.

Kutas, M., \& Hillyard, S.A. (1980). Reading senseless sentences: Brain potentials reflect semantic incongruity. Science, 207, 203-205.

Kutas, M., \& Hillyard, S.A. (1983). Event-related potentials to grammatical errors and semantic anomalies. Memory and Cognition, 11, 539-550.

Kutas, M., \& Federmeier, K.D. (2000). Electrophysiology reveals semantic memory use in language comprehension. Trends in Cognitive Science, 4, 463-470.

MacDonald, M.C., Pearlmutter, N.J., \& Seidenberg, M.S. (1994). The lexical nature of syntactic ambiguity resolution. Psychological Review, 101, 676-703.

Mecklinger, A., Schriefers, H., Steinhauer, K., \& Friederici, A.D. (1995). Processing relative clauses varying on syntactic and semantic dimensions: An analysis with event-related potentials. Journal of Memory and Cognition, 23, 477-494.

Münte, T.F., Heinze, H., \& Mangun, G.R. (1993). Dissociation of brain activity related to syntactic and semantic aspects of language. Journal of Cognitive Neuroscience, 5, 335-344.

Neville, H.J., Nicol, J., Barss, A., Forster, K., \& Garrett, M.F. (1991). Syntactically based sentence processing classes: Evidence from event-related potentials. Journal of Cognitive Neuroscience, 6, 233-255.

Osterhout, L., \& Holcomb, P.J. (1992). Event-related brain potentials elicited by syntactic anomaly. Journal of Memory and Language, 31, 785-804.

Osterhout, L., \& Holcomb, P.J. (1993). Event-related brain potentials and syntactic anomaly: Evidence of anomaly detection during the perception of continuous speech. Language and Cognitive Processes, 8, 413-437.

Osterhout, L., Holcomb, P.J., \& Swinney, D.A. (1994). Brain potentials elicited by gardenpath sentences: Evidence of the application of verb information during parsing. Journal of Experimental Psychology: Learning, Memory, and Cognition, 20, 786-803. 
Primus, B. (1998). The relative order of recipient and patient in the languages of Europe. In A. Siewierska (Ed.), Constituent order in the languages of Europe (pp. 421-471). Berlin: Mouton de Gruyter.

Primus, B. (1999). Cases and thematic roles. Tübingen: Niemeyer.

Pulvermüller, F., Assadollahi, R., \& Elbert, T. (2001). Neuromagnetic evidence for early semantic access in word recognition. European Journal of Neuroscience, 13, 201-205.

Rayner, K., Carlson, K., \& Frazier, L. (1983). The interaction of syntax and semantics during sentence processing: Eye-movements in the analysis of semantically biased sentences. Journal of Verbal Learning and Verbal Behavior, 22, 358-374.

Rösler, F., Friederici, A.D., Pütz, P., \& Hahne, A. (1993). Event-related brain potentials while encountering semantic and syntactic constraint violations. Journal of Cognitive Neuroscience, $5,345-362$.

Rösler, F., Pechmann, T., Streb, J., Röder, B., \& Hennighausen, E. (1998). Parsing of sentences in a language with varying word order: Word-by-word variations of processing demands are revealed by event-related brain potentials. Journal of Memory and Language, 38, 150-176.

Scheepers, C., Hemforth, B., \& Konieczny, L. (2000). Linking syntactic functions with thematic roles: Psych-verbs and the resolution of subject-object ambiguity. In B. Hemforth \& L. Konieczny (Eds.), German sentence processing (pp. 95-135). Dordrecht: Kluwer.

Schlesewsky, M., Bornkessel, I., \& Frisch, S. (in press). The neurophysiological basis of word order variations in German. Brain and Language.

Sharbrough, F., Chatrian, G.-E., Lesser, R.P., Lüders, H., Nuwer, M., \& Picton T.W. (1991). American Encephalographic Society guidelines for standard electrode position nomenclature. Journal of Clinical Neurophysiology, 8, 200-202.

Skrandies, W. (1998). Evoked potential correlates of semantic meaning-a brain mapping studyy. Cognitive Brain Research, 6, 173-183.

Stabler, E.P. (1994). The finite connectivity of linguistic structure. In C. Clifton, L. Frazier, \& K. Rayner (Eds.), Perspectives on sentence processing (pp. 303-336). Hillsdale, NJ: Lawrence Erlbaum Associates Inc.

Steinhauer, K., Mecklinger, A., Friederici, A.D., \& Meyer, M. (1997). Wahrscheinlichkeit und Strategie: Eine EKP-Studie zur Verarbeitung syntaktischer Anomalien. Zeitschrift für Experimentelle Psychologie, XLIV(2), 305-331.

Tomlin, R. (1986). Basis word order. Functional principles. London: Croomhelm.

Trueswell, J.C., Tanenhaus, M.K., \& Garnsey, S. M. (1994). Semantic influences on parsing: Use of thematic role information in syntactic disambiguation. Journal of Memory and Language, 33, 285-318.

Van Petten, C.K., \& Kutas, M. (1991). Influences of semantic and syntactic context on openand closed-class words. Memory and Cognition, 19, 95-112.

Van Valin, R.D., Jr., \& La Polla, R. J. (1997). Syntax: Structure, meaning and function. Cambridge: Cambridge University Press.

Wegener, H. (1985). Der Dativ im heutigen Deutsch. Tübingen: Narr.

Wunderlich, D. (1985). Über die Argumente des Verbs. Linguistische Berichte, 97, 183-227.

Wunderlich, D. (1997). Cause and the structure of verbs. Linguistic Inquiry, 28, 27-68.

Zubin, D.A., \& Köpke, K.-M. (1985). Cognitive constraints on the order of subject and object in German. Studies in Language, 9, 77-101. 